\title{
Extended Long-Term (5 Years) Outcomes of Triangle Tilt Surgery in Obstetric Brachial Plexus Injury
}

\author{
Rahul K. Nath* and Chandra Somasundaram
}

Texas Nerve and Paralysis Institute, 6400 Fannin Street, Houston, Texas, 77030, USA

\begin{abstract}
Objective: We evaluated the "extended" long-term (5 years) functional outcomes in obstetric brachial plexus injury (OBPI) patients, who underwent triangle tilt surgery between February 2005 and January 2008.

Methods: Twenty two children (9 girls and 13 boys, mean age at surgery was 5.8 years; ranging 2.1-11.8 years old), who initially presented with medial rotation contracture and scapula deformity secondary to obstetric brachial plexus injury were included in this study. Functional movements were evaluated pre-operatively, and 5 years following triangle tilt surgery by modified Mallet scale.

Results: Here, we report long-term ( 5 years) follow-up of triangle tilt surgery for 22 OBPI patients. Upper extremity functional movements such as, external rotation $(2.5 \pm 0.6$ to $4.1 \pm 0.8, \mathrm{p}<0.0001)$, hand-to-spine $(2.6 \pm 0.6$ to $3.4 \pm 1.1$, $\mathrm{p}<0.005)$, hand-to-neck $(2.7 \pm 0.7$ to $4.3 \pm 0.7, \mathrm{p}<0.0001)$, hand-to-mouth $\left(2.3 \pm 0.9\left(92^{\circ} \pm 33\right)\right.$ to $\left.4.2 \pm 0.5\left(21^{\circ} \pm 16\right), \mathrm{p}<0.0001\right)$, and supination $\left(2.6 \pm 1.1\left(-8.2^{\circ} \pm 51\right)\right.$ to $4.1 \pm 0.7(61 \pm 32)$ ) were significantly improved $(\mathrm{p}<0.0001)$, and maintained over the extended long-term (5 years). Total modified Mallet functional score was also shown to improve from $14.1 \pm 2.7$ to $20.3 \pm 2.5$.
\end{abstract}

Conclusions: The triangle tilt surgery improved all shoulder functions significantly, and maintained over the extended long-term (5 years) in these patients.

Keywords: Obstetric brachial plexus injury, triangle tilt surgery, modified Mallet score, extended long-term, upper extremity function.

\section{INTRODUCTION}

Recent published epidemiological study identified an incidence of about $0.15 \%$ obstetric brachial plexus injury in live births in USA [1]. Despite the advances in technology, the rate of occurrence has remained stable [2]. Although, most injuries are transient and recover function spontaneously within the 3 months of life, some result in prolonged and persistent disability. Traditional approaches to treat OBPI are nerve and tendon transfers, muscle releases, axillary nerve decompression and derotational osteotomy of the humerus [3-11]. These surgical procedures may lead to better shoulder abduction and flexion, and improve the resting position of the arm. However, these procedures may not address the glenohumeral dysplasia and joint incongruity, which impair the bone growth and development [12]. The triangle tilt surgery was developed by the surgeon (RKN) to mainly correct this bony deformity and shown to have a high success rate [13-23].

The short (1 year), and long-term (2 years) benefits of triangle tilt surgery in OBPI patients were previously demonstrated by examination of their radiological reports as well as the modified Mallet functional scale [13, 19]. Now, we evaluated the "extended" long-term functional outcomes

*Address correspondence to this author at the Texas Nerve and Paralysis Institute, 6400 Fannin Street, Houston, Texas, 77030, USA;

Tel: 1-713-592-9900; Fax: 1-713-592-9921;

E-mail: drnath@drnathmedical.com
( 5 years) of triangle tilt in 22 OBPI patients, who underwent this surgery between February 2005 and January 2008 at our institute.

\section{METHODS AND PATIENTS}

266 OBPI patients have undergone triangle tilt surgery between February 2005 and January 2008, at our institute. 22 patients were included in this study, who have completed 5year follow-up. The brachial plexus injuries involved C5-C6 nerve roots in 11 patients, $\mathrm{C} 5-\mathrm{C} 7$ nerve roots in 7 patients, and $\mathrm{C} 5-\mathrm{C} 8$ or $\mathrm{C} 5-\mathrm{T} 1$ nerve roots in 4 patients. All the patients in this study had already undergone the modified Quad soft tissue release procedure [11] to improve their shoulder abduction. Some of the patients have had primary nerve surgery, and other secondary procedures, such as posterior glenohumeral capsulorrhaphy, and humeral osteotomy at other institutions. However, these procedures failed to resolve the shoulder deformity in these patients. The medial rotation contracture was still persistent in these patients, even after the patients have undergone one or two of the above mentioned procedures, physiotherapy and/or splinting.

The triangle tilt operative technique includes osteotomies of the clavicle, neck of the acromion and scapula in order to release the distal acromioclavicular triangle and allow it to reorient itself in a more neutral position into the glenoid [1323]. The lead author and surgeon, who has over 17 years of experience with obstetric brachial plexus injury, performed all the surgical procedures, and evaluated the pre- and 
postoperative shoulder functions of these patients in the clinic. Further, the trained scientist (independent of the surgeon) also scored modified Mallet from photo/video records of these patients [24].

Modified Mallet functional evaluation was performed for five-year follow-up (at the mean time of 62 months,), and these data were compared statistically with pre-operative data.

The paired student's t-test statistics was applied to compare the pre- and post-triangle tilt mean Mallet scores using the Analyze it plug in (Leeds, UK) for Microsoft Excel 2003. A value of $\mathrm{p}<0.05$ was considered statistically significant.

\section{RESULTS}

There was an overall significant upper extremity functional improvements (Table 1), and significant difference in total modified Mallet score following 5-year after triangle tilt surgery in these patients (Fig. 1). Pre- and post-operative hand to mouth, and supination angles were compared statistically and reported (Figs. 2, 3). Modified Mallet functional movements and apparent supination were evaluated for each patient and reported (Figs. 4, 5).

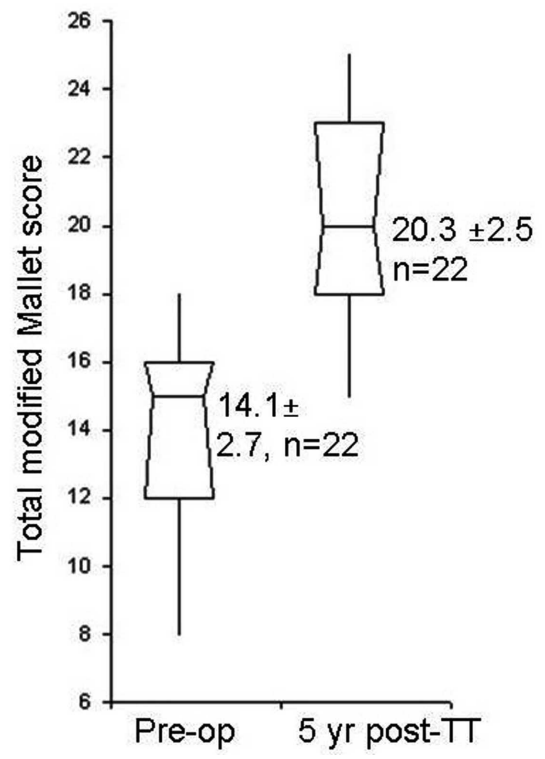

Fig. (1). Comparison of total modified Mallet score pre-operatively and five-year follow-up of triangle tilt surgery in 22 OBPI patients. $p<0.0001$.

Upper extremity functional movements such as, external rotation $(2.5 \pm 0.6$ to $4.1 \pm 0.8, \quad \mathrm{p}<0.0001)$, hand-to-spine $(2.5 \pm 0.6$ to $3.4 \pm 1.1, \mathrm{p}<0.005)$, hand-to-neck $(2.7 \pm 0.7$ to $4.3 \pm 0.7, \mathrm{p}<0.0001)$, hand-to-mouth $\left(2.3 \pm 0.9 \quad\left(92^{\circ} \pm 33\right)\right.$ to $\left.4.2 \pm 0.5\left(21^{\circ} \pm 16\right), \mathrm{p}<0.0001\right)$, and supination $\left(2.6 \pm 1.1\left(-8.2^{\circ}\right.\right.$ $\pm 51)$ to $4.1 \pm 0.7(61 \pm 32))$ were significantly improved $(\mathrm{p}<0.0001)$, and maintained over the extended long-term (5 years). Total modified Mallet functional score was also shown to improve from $14.1 \pm 2.7$ to $20.3 \pm 2.5(\mathrm{p}<0.0001)$.

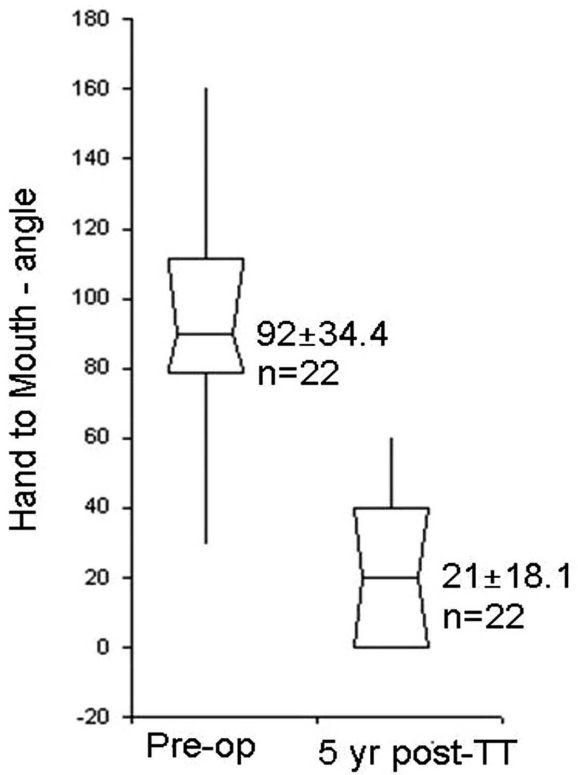

Fig. (2). Comparison of hand-to-mouth movement (angle) preoperatively and five-year follow-up of triangle tilt surgery in 22 OBPI patients. $p<0.0001$

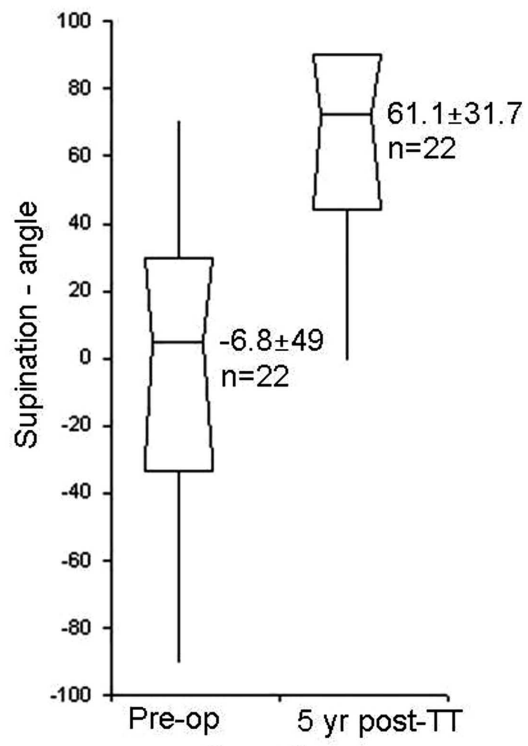

Fig. (3). Comparison of supination angle pre-operatively and fiveyear follow-up of triangle tilt surgery in 22 OBPI patients. $p<$ 0.0001 .

Table 1. Comparison of Modified Mallet Score in OBPI Patients in Long-Term (5 Years) Follow-Up of Triangle Tilt Surgery

\begin{tabular}{|c|c|c|c|c|c|c|}
\hline & External Rotation* & Hand to Neck* & Hand to Spine** & Hand to Mouth* & Supination* & Total Mallet* \\
\hline \hline Pre-op & $2.5 \pm 0.6$ & $2.7 \pm 0.7$ & $2.5 \pm 0.6$ & $2.3 \pm 0.9\left(92^{\circ} \pm 33\right)$ & $2.6 \pm 1.1\left(-8.2^{\circ} \pm 51\right)$ & $14.1 \pm 2.7$ \\
\hline post-op 5-years & $4.1 \pm 0.8$ & $4.3 \pm 0.7$ & $3.4 \pm 1.1$ & $4.2 \pm 0.5\left(21^{\circ} \pm 16\right)$ & $4.1 \pm 0.7(61 \pm 32)$ & $20.3 \pm 2.5$ \\
\hline
\end{tabular}



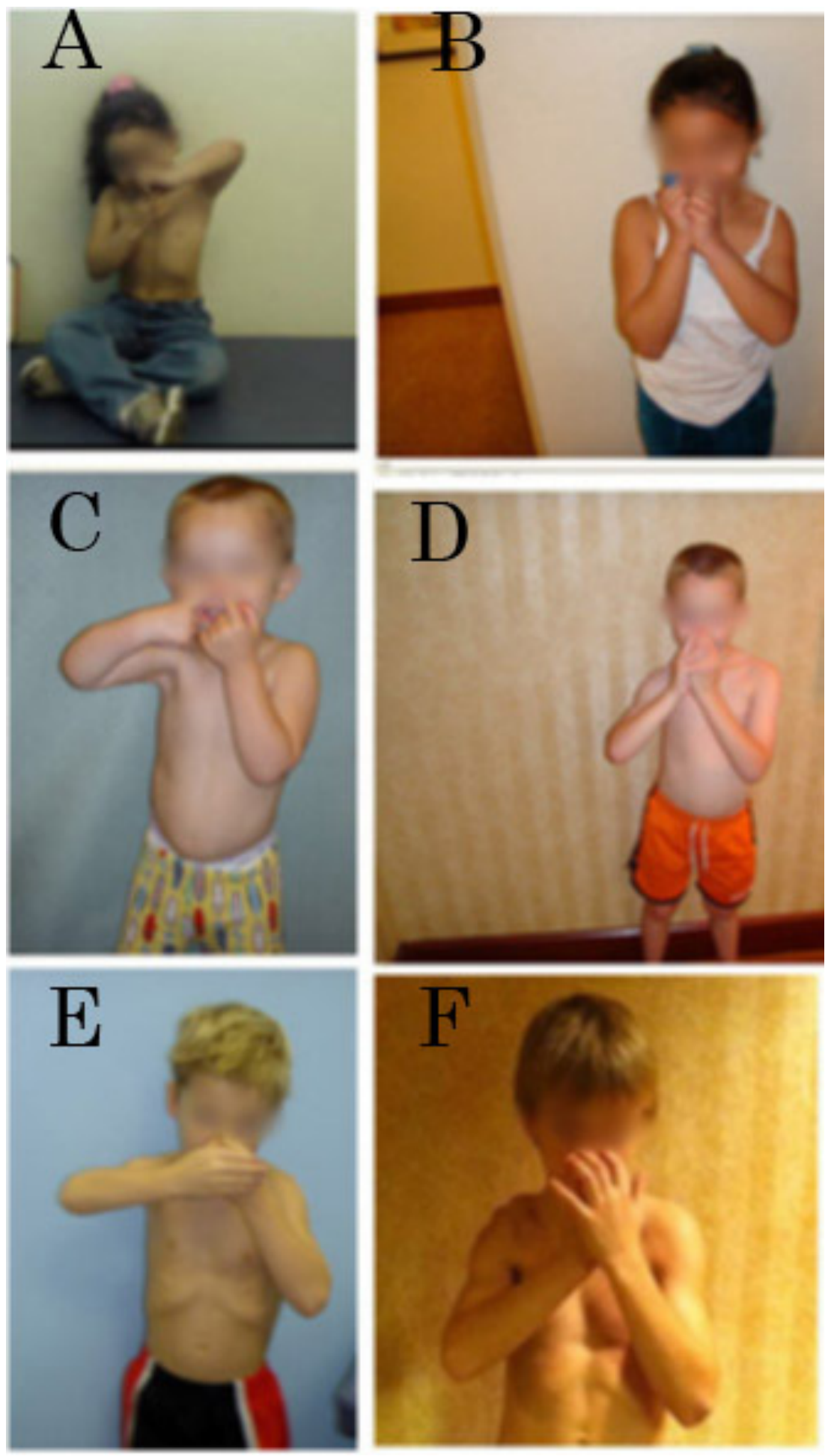

Fig. (4). Comparison of pre- and post-operative hand-to-mouth movement in OBPI patients. Preoperative photograph of a 5.8-year old girl (A), 2-year-old boy (C), and a 4.2-year-old boy (E), demonstrating limitation of hand-to-mouth function with typical bugler's position. Same patients, 59, 61 and 62 months after triangle tilt surgery respectively $(\mathbf{B}, \mathbf{D}$ and $\mathbf{F})$.

\section{DISCUSSION}

We have previously reported short-term (1 year) followup of triangle tilt surgery for 44 patients [13], and 2 year follow-up of this surgery for 61 patients [19]. Further, we report here extended long-term follow-up (5 years) of triangle tilt procedure for 22 patients.
All the patients included in this study had undergone a modified Quad procedure [11] prior to triangle tilt surgery, which significantly improved their shoulder abduction to a mean score of 4.3 or about $160^{\circ}$. Modified Quad procedure releases the soft tissue contractures, which greatly improves the shoulder abduction and flexion, but does not correct the glenohumeral joint incongruence. In order to address this, 

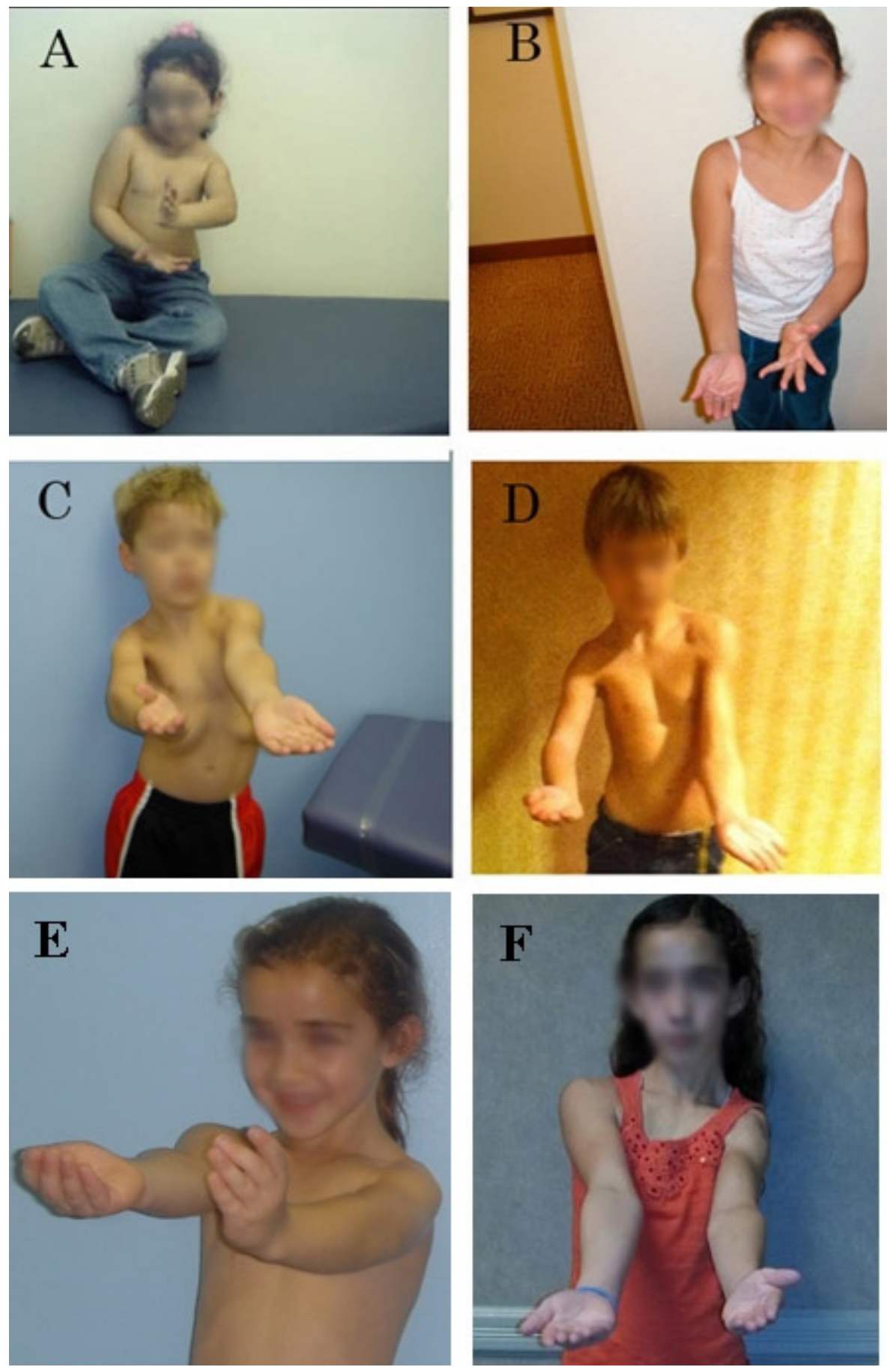

Fig. (5). Comparison of pre- and post-operative apparent supination in OBPI patients. Preoperative photograph of a 5.8-year old girl (a), a 4.2 year old boy $(\mathbf{C})$ and a 6.2 year old girl (E), demonstrating limitation of apparent supination; same patients, 59, 62 and 60 months after triangle tilt surgery respectively $(\mathbf{B}, \mathbf{D}$ and $\mathbf{F})$.

the triangle tilt [13-23], a unique bony surgical intervention has been performed on these patients. This procedure realigns the glenohumeral joint, and improves the other upper extremity functions such as external rotation, hand to mouth, and neck [13-23].

Though several surgical procedures have been explored in an effort to treat abnormal shoulder development of these OBPI patients $[25,26]$, only a few procedures are successful in long-term of improvements both functionally and anatomically. Investigators in this field demonstrated the use of tendon transfer/lengthening, and open reduction to improve shoulder functions and glenohumeral deformity in selected OBPI patients with mild-to-moderate glenohumeral deformity with posterior subluxation [25].

Patients ( 2 to 12 years) treated with triangle tilt surgery in our present study were with more severe initial deformity of the glenohumeral joint according to the grading criteria $[27,28]$. Posterior subluxation ranged from $-60 \%$ to $40 \%$ and glenoid version ranged from $-75^{\circ}$ to $-8^{\circ}$ for affected shoulders preoperatively (data not shown). After the triangle 
tilt surgery, patients gained remarkable functional improvements (Table $\mathbf{1}$ and Figs. 1-5), even for those with more severely deformed glenohumeral joints, which is consistent with our previously published study [13]. These functional movements continued to improve as shown in Figs. (1-5) in 5 year follow-up, when compared to the short term follow-up [13], and further these functions were maintained over long-term. We have demonstrated earlier that these patients also showed significant glenohumeral remodeling or reservation of glenoid congruence [19] in 2 year (over a mean time of 27 months) follow-up of triangle tilt surgery.

\section{CONCLUSIONS}

The triangle tilt surgery improved all shoulder functions highly significantly in 5-year follow-up, and further the functions were maintained over extended time in these patients.

\section{AUTHORS' CONTRIBUTIONS}

RKN designed the study, performed the surgeries, and revised the manuscript. CS carried out the measurements, performed the statistical analysis and wrote the manuscript. Both authors read and approved the final manuscript.

\section{CONFLICT OF INTEREST}

The authors confirm that this article content has no conflict of interest.

\section{ACKNOWLEDGEMENTS}

Declared none.

\section{REFERENCES}

[1] Foad SL, Mehlman CT, Ying J. The epidemiology of neonatal brachial plexus palsy in the United States. J Bone Joint Surg Am 2008; 90: 1258-64.

[2] Zafeiriou DI, Psychogiou K. Obstetrical brachial plexus palsy. Pediatr Neurol 2008; 38: 235-42.

[3] Pagnotta A, Haerle M, Gilbert A. Long-term results on abduction and external rotation of the shoulder after latissimus dorsi transfer for sequelae of obstetric palsy. Clin Orthop Relat Res 2004; 426: 199-205.

[4] Hoffer MM, Phipps GJ. Closed reduction and tendon transfer for treatment of dislocation of the glenohumeral joint secondary to brachial plexus birth palsy. J Bone Joint Surg Am 1998; 80: 9971001.

[5] Safoury Y. Muscle transfer for shoulder reconstruction in obstetrical brachial plexus lesions. Handchir Mikrochir Plast Chir 2005; 37: 332-6

[6] Waters PM, Bae DS. Effect of tendon transfers and extra-articular soft-tissue balancing on glenohumeral development in brachial plexus birth palsy. J Bone Joint Surg Am 2005; 87: 320-5.

[7] Waters PM, Bae DS. The effect of derotational humeral osteotomy on global shoulder function in brachial plexus birth palsy. J Bone Joint Surg Am 2006; 88: 1035-42.

[8] Al-Qattan MM. Latissimus dorsi transfer for external rotation weakness of the shoulder in obstetric brachial plexus palsy. J Hand Surg Br 2003; 28: 487-90.

[9] Bahm J, Ocampo-Pavez C. Monopolar teres major muscle transposition to improve shoulder abduction and flexion in children with sequelae of obstetric brachial plexus palsy. J Brachial Plex Peripher Nerve Inj 2009; 4: 20.

[10] Nath RK, Somasundaram C. Successful outcome of modified quad surgical procedure in preteen and teen patients with brachial plexus birth palsy. Eplasty 2012; 12: e54.

[11] Nath RK, Paizi M. Improvement in abduction of the shoulder after reconstructive soft-tissue procedures in obstetric brachial plexus palsy. J Bone Joint Surg Br 2007; 89: 620-6.

[12] Birch R, Bonney G, Wynn Parry CB. Birth lesions of the brachial plexus. In: Surgical disorders of the peripheral nerves. In: Birch R, Bonney G, Wynn Parry CB, Eds. New York, NY: Churchill Livingstone 1998; pp. 209-33

[13] Nath RK, Melcher SE, Lyons AB, Paizi M. Surgical correction of the medial rotation contracture in obstetric brachial plexus palsy. J Bone Joint Surg Br 2007; 89: 1638-44.

[14] Nath RK, Melcher SE, Paizi M. Surgical correction of unsuccessful derotational humeral osteotomy in obstetric brachial plexus palsy: Evidence of the significance of scapular deformity in the pathophysiology of the medial rotation contracture. J Brachial Plex Peripher Nerve Inj 2006; 1: 9.

[15] Nath RK, Karicherla P, Mahmooduddin F. Shoulder function and anatomy in complete obstetric brachial plexus palsy: long-term mprovement after triangle tilt surgery. Childs Nerv Syst 2010; 26(8): 1009-19.

[16] Nath RK, Avila MB, Karicherla P. Triangle tilt surgery as salvage procedure for failed shoulder surgery in obstetric brachial plexus injury. Pediatr Surg Int 2010; 26(9): 913-8.

[17] Nath RK, Abdelouahed A, Melcher SE, Wentz MJ, Paizi M. Surgical normalization of the shoulder joint in obstetric brachial plexus injury. Ann Plast Surg 2010; 65(4): 411-7.

[18] Nath RK, Amrani A, Melcher SE, Eichhorn MG. Triangle tilt surgery in an older pediatric patient with obstetric brachial plexus injury. Eplasty 2009; 9: e26.

[19] Nath RK, Liu X, Melcher SE, Fan J. Long-term outcomes of triangle tilt surgery for obstetric brachial plexus injury. Pediatr Surg Int 2010; 26: 393-9.

[20] Nath RK, Somasundaram C, Melcher SE, Bala M, Wentz MJ. Arm rotated medially with supination - the ARMS variant: description of its surgical correction. BMC Musculoskelet Disord 2009; 10: 32.

[21] Nath RK, Somasundaram C, Mahmooduddin F. Comparing functional outcome of triangle tilt surgery performed before versus after two years of age. Open Orthop J 2011; 5: 59-62.

[22] Nath RK, Somasundaram C, Mahmooduddin F. Triangle tilt and steel osteotomy: similar approaches to common problems. Open Orthop J 2011; 5: 124-33.

[23] Nath RK, Amrani A, Melcher SE, Wentz MJ, Paizi M. Surgical normalization of the shoulder joint in obstetric brachial plexus injury. Ann Plast Surg 2010; 65: 411-7.

[24] Mallet J. Obstetrical paralysis of the brachial plexus. II. Therapeutics. Treatment of sequelae. e. Results of different therapeutic techniques and therapeutic indications. Rev Chir Orthop Reparatrice Appar Mot 1972; 58: 192-6.

[25] Waters PM, Bae DS. The early effects of tendon transfers and open capsulorrhaphy on glenohumeral deformity in brachial plexus birth palsy. J Bone Joint Surg Am 2008; 90: 2171-9.

[26] Pearl ML, Edgerton BW, Kazimiroff PA, Burchette RJ, Wong K. Arthroscopic release and latissimus dorsi transfer for shoulder internal rotation contractures and glenohumeral deformity secondary to brachial plexus birth palsy. J Bone Joint Surg Am 2006; 88: 564-74.

[27] Waters PM, Smith GR, Jaramillo D. Glenohumeral deformity secondary to brachial plexus birth palsy. J Bone Joint Surg Am 1998; 80: 668-77.

[28] Pearl ML, Edgerton BW, Kon DS, et al. Comparison of arthroscopic findings with magnetic resonance imaging and arthrography in children with glenohumeral deformities secondary to brachial plexus birth palsy. J Bone Joint Surg Am 2003; 85: 8908. 